\title{
Domains of yeast U4 spliceosomal RNA required for PRP4 protein binding, snRNP-snRNP interactions, and pre- mRNA splicing in vivo
}

\author{
Rémy Bordonné, Josette Banroques, ${ }^{1,2}$ John Abelson, ${ }^{1}$ and Christine Guthrie ${ }^{3}$ \\ Department of Biochemistry and Biophysics, University of California at San Francisco, San Francisco, California 94143 USA; \\ 'Division of Biology, California Institute of Technology, Pasadena, California 91125 USA
}

U4 small nuclear RNA (snRNA) contains two intramolecular stem-loop structures, located near each end of the molecule. The 5' stem-loop is highly conserved in structure and separates two regions of U4 snRNA that basepair with U6 snRNA in the U4/U6 small nuclear ribonucleoprotein particle (snRNP). The $3^{\prime}$ stem-loop is highly divergent in structure among species and lies immediately upstream of the binding site for $\mathrm{Sm}$ proteins. To investigate the function of these two domains, mutants were constructed that delete the yeast U4 snRNA ${ }^{\prime}{ }^{\prime}$ stem-loop and that replace the yeast $3^{\prime}$ stem-loop with that from trypanosome U4 snRNA. Both mutants fail to complement a null allele of the yeast $U 4$ gene. The defects of the mutants have been examined in heterozygous strains by native gel electrophoresis, glycerol gradient centrifugation, and immunoprecipitation. The chimeric yeast-trypanosome RNA does not associate efficiently with U6 snRNA, suggesting that the $3^{\prime}$ stem-loop of yeast U4 snRNA might be a binding site for a putative protein that facilitates assembly of the U4/U6 complex. In contrast, the 5' hairpin deletion mutant associates efficiently with U6 snRNA. However, it does not bind the U4/U6-specific protein PRP4 and does not assemble into a U4/U5/U6 snRNP. Thus, we propose that the role of the PRP4 protein is to promote interactions between the U4/U6 snRNP and the U5 SnRNP.

[Key Words: U6 snRNA; RNA-protein and protein-protein interactions; Sm-binding site]

Received February 20, 1990; revised version accepted April 9, 1990.

Splicing of nuclear pre-mRNA in yeast and mammals occurs in a large complex termed the spliceosome, which contains U1, U2, U4/U6, and U5 small nuclear ribonucleoprotein particles (snRNPs) (for review, see Maniatis and Reed 1987; Sharp 1987). Whereas U1, U2, and U5 small nuclear RNAs (snRNAs) exist in separate ribonucleoprotein particles (for review, see Lührmann 1988; Reddy and Busch 1988), the U4 and U6 snRNAs exist in a single snRNP (Bringmann et al. 1984; Hashimoto and Steitz 1984). It has been shown that both RNAs are essential for splicing in mammals and the yeast Saccharomyces cerevisiae (Berget and Robberson 1986; Black and Steitz 1986; Siliciano et al. 1987; Brow and Guthrie 1988), yet the function of this snRNP is still unknown. In contrast to other yeast spliceosomal snRNAs, the yeast U4 and U6 snRNAs are very similar in size to their mammalian counterparts and $\mathrm{U} 6$ is highly conserved in primary sequence /Guthrie and Patterson 1988).

In vitro studies on spliceosomal assembly provide evi-

2Present address: Ecole Normale Supérieure, Laboratoire de Génetique Moléculaire, 75005 Paris, France.

${ }^{3}$ Corresponding author. dence for a key role of the U4/U6 snRNP in the splicing reaction. After association of $U 1$ and $U 2$ snRNPs to the pre-mRNA, the U4/U6 snRNP is delivered to the spliceosome perhaps as a tripartite complex with the U5 snRNP (Pikielny et al. 1986; Bindereif and Green 1987; Cheng and Abelson 1987; Konarska and Sharp 1987; Lamond et al. 1988). The transition to a catalytically active spliceosome is marked by dissociation of the U4 snRNA from the spliceosome (Pikielny et al. 1986; Cheng and Abelson 1987; Konarska and Sharp 1988; Lamond et al. 1988 ) or at least a large conformational rearrangement of the U4/U6 snRNP (Blencowe et al. 1989). Because of the remarkable conservation of U6, it has been suggested that this RNA may be involved in catalysis of premRNA and that U4 acts to negatively regulate U6 activity (Brow and Guthrie 1989).

A secondary structure model of U4 and U6 snRNAs has been proposed by Brow and Guthrie (1988). The snRNAs interact extensively via base-pairing to form two intermolecular helices (stem I and stem II) and a U4 5' stem-loop structure (Fig. 1). The existence of stem I has been shown by cross-linking experiments (Rinke et al. 1985), and the characteristic " $\mathrm{Y}$ " folding of the inter- 


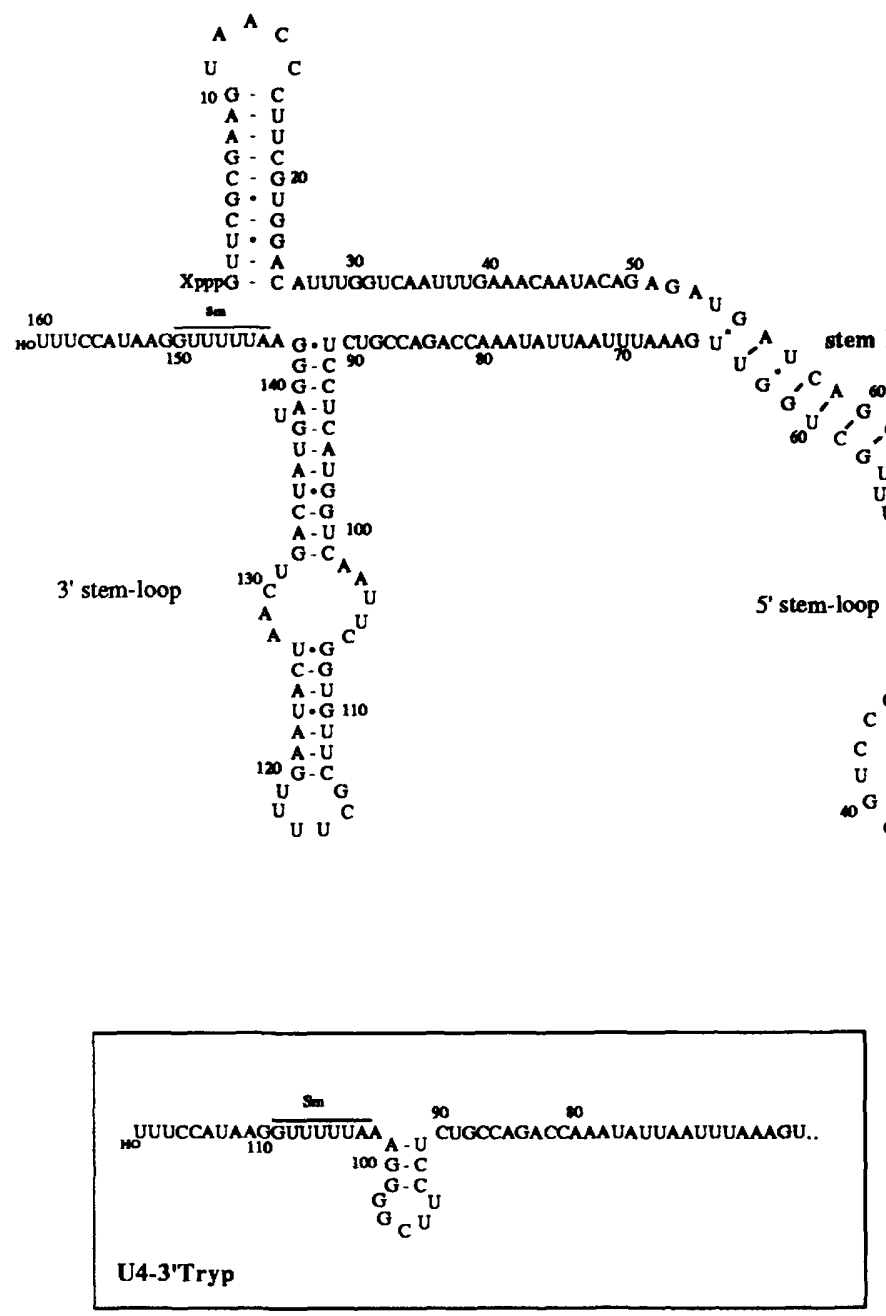

yeast U6 20 GAACOGUUUUUACAaAGaGaUUUAUUUCGUUUU OH G G, $c$ A ${ }^{A} \mathrm{C}$ stem II ${ }^{20}, C_{V}, G^{\prime} U$ yeast U4 $c{ }^{\circ} \mathrm{C}_{10}$ $c,{ }^{C} \mathrm{G}$

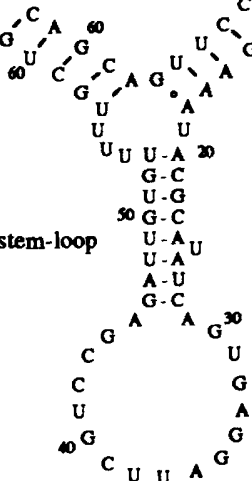

Figure 1. Secondary structure of the yeast U4/U6 snRNA molecules, as proposed by Brow and Guthrie (1988). The insets represent the position, sequence, and predicted secondary structure of the U4 deletion and substitution mutants. (U4DSL) Deletion of nucleotides 19-52 of the yeast U4 snRNA; (U4AL) deletion of nucleotides 31-43; (U4-3'Tryp) substitution of nucleotides 91-142 with the corresponding sequence of trypanosome U4 snRNA (nucleotides 74-84; Mottram et al. 1989). The sequence of a potential Sm-binding site in yeast $\mathrm{U} 4 \mathrm{RNA}$ is overlined.

action domain is conserved phylogenetically /Guthrie and Patterson 1988).

In yeast and mammals, one set of polypeptides associated with the U4/U6 SnRNP is represented by the common core proteins (known as Sm proteins), which react with human autoimmune sera of $\mathrm{Sm}$ specificity (Lerner and Steitz 1979; Bringmann and Lührmann 1986; Lehay-Taha et al. 1986; Riedel et al. 1987; Tollervey and Mattaj 1987; for review, see Lührmann 1988). A conserved motif $A\left(U_{3-6}\right) G$ is found in $U 1, U 2, U 4$, and U5 snRNAs, and this Sm-bindng site is essential for binding of the core polypeptides (Branlant et al. 1982; Mattaj and DeRobertis 1985). The U6 snRNA lacks such an Sm-binding site but can be immunoprecipitated by anti-Sm sera because it associates with U4 snRNA (Bringmann et al. 1984; Hashimoto and Steitz 1984). Besides these common core proteins, no additional U4/U6 snRNP proteins are known in mammals. In $S$. cerevi- siae, one specific U4/U6 snRNP protein, named PRP4, has been described (Banroques and Abelson 1989; Petersen-Bjørn et al. 1989). In low salt conditions, the U5 snRNA can be coprecipitated with U4 and U6 snRNAs by anti-PRP4 antibodies (Banroques and Abelson 1989; Petersen-Bjørn et al. 1989|. Conversely, a second protein, PRP8, is specifically associated with the yeast U5 snRNA, but U4 and U6 snRNAs are coprecipitated by anti-PRP8 antibodies upon incubation of the extracts with ATP (Lossky et al. 1987). The functions of these proteins are unknown.

In vitro reconstitution systems have been developed recently, both in mammals and yeast, for the study of the U4/U6 snRNP (Fabrizio et al. 1989; Pikielny et al. 1989; Bindereif et al. 1990). However, in these studies the structural requirements of U4 snRNA were not assayed. In this work, we took advantage of the genetic tools available in $S$. cerevisiae to assess the roles of spe- 
cific regions of $U 4$ in the in vivo assembly of functional snRNPs. Our analysis suggests that the phylogenetically conserved $5^{\prime}$ stem-loop is required for the binding of the PRP4 protein, as well as for the association of the U4/U6 snRNP with the U5 snRNP. In addition, we show that an interspecies swap between the 3' stem-loops of the yeast and trypanosome U4 snRNAs results in a chimeric snRNA that does not associate efficiently with U6. Thus, in addition to base-pairing in stem I and stem II, other interactions appear to be required to promote U4/U6 complex formation.

\section{Results \\ U4 mutant RNAs are nonfunctional but are incorporated into snRNPs}

In yeast, U4 snRNA is encoded by a single-copy essential gene called SNR14 (Siliciano et al. 1987). Two deletions and one substitution were introduced into the SNR14 gene by site-directed mutagenesis (Kunkel et al. 1987), and the mutants were further subcloned into the yeast centromeric vector pKE362 containing the HIS3 gene. The predicted structures of the three mutant $U 4$ snRNAs are shown in Figure 1. The mutant U4DSL contains a deletion of the $5^{\prime}$ stem-loop structure separating stem I and stem II of the U4/U6 interaction domain. The second mutant, called $\mathrm{U} 4 \Delta \mathrm{L}$, lacks most of the highly conserved loop (nucleotides 31-43) but possesses the intact stem from this intramolecular domain. Finally, the mutant U4-3'Tryp, was constructed by substitution of the 52 nucleotides from the yeast $S$. cerevisiae $3^{\prime}$ stemloop with the 11-nucleotide stem-loop region (nucleotides 74-84) of the U4 snRNA from Trypanosoma brucei (Mottram et al. 1989). Each mutant retains the consensus binding site for the Sm proteins (nucleotides 144-150; see Fig. 1).

The plasmid shuffle technique was used to determine the effect of the mutant U4 RNAs in vivo /see Materials and methods). The plasmids carrying the mutant U4 genes, U4 $\Delta \mathrm{SL}, \mathrm{U} 4 \Delta \mathrm{L}$, and U4-3'Tryp, were transformed into strains carrying a wild-type U4 gene. Heterozygous cells did not show any growth defect, indicating that the mutants had no obvious dominant phenotype. However, each of the mutant strains failed to grow on plates containing 5-fluoroorotic acid (FOA) at $18,25,30$, and $37^{\circ} \mathrm{C}$, indicating that cells carrying only the mutant genes are not viable. To assess whether the growth defect was due to a functional impairment rather than to instability of the mutant RNAs, we prepared RNA from the heterozygous strains and performed Northern analysis. As shown in Figure 2, the U4ASL and U4-3'Tryp RNAs are expressed and possess the expected length. In contrast, no $\mathrm{U} 4 \Delta \mathrm{L}$ mutant RNA is detected (Fig. 2, lane 4). The instability of this particular mutant may be due to the formation of an alternate tertiary structure that does not allow the binding of the core protein to the RNA. The properties of the three U4 mutants are summarized in Table 1.

To investigate further the properties of the U4ASL and U4-3'Tryp mutants, RNA was immunoprecipitated

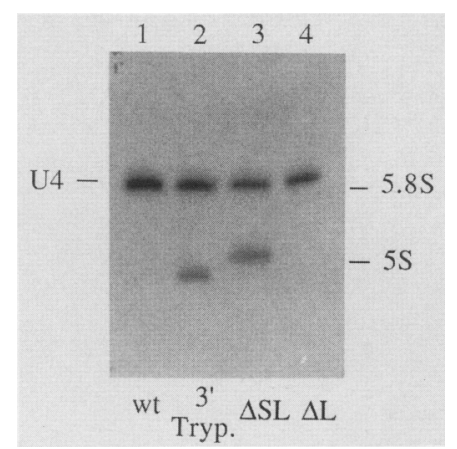

Figure 2. Northern blot analysis of in vivo-assembled U4 mutant snRNAs. Total RNA prepared from heterozygous strains RBU4 $\Delta$ SL, RBU4 $\Delta$ L, and RBU4-3'Tryp, carrying both the wildtype U4 gene and the corresponding mutant gene, were transferred to nylon membrane after separation on a denaturing polyacrylamide gel. The blot was probed with a mixture of ${ }^{32} \mathrm{p}$ labeled oligonucleotide $14 \mathrm{C}$ (which hybridizes to the wild-type U4 and U4-3'Tryp RNAs) and oligonucleotide 14B (which hybridizes to wild-type $\mathrm{U} 4, \mathrm{U} 4 \Delta \mathrm{SL}$, and $\mathrm{U} 4 \Delta \mathrm{L}$ RNAs). Lane $w t$ corresponds to RNA extracted from the wild-type strain RBU4wt containing two wild-type U4 genes, one carried by a YCp50 vector and the other by a pKE362 vector. The lengths of $5.8 \mathrm{~S}$ and 5S RNAs are 158 and 121 nucleotides, respectively. The abbreviations used are the same as those in Fig. 1.

from splicing extracts prepared from heterozygous strains carrying wild-type and mutant U4 RNA genes. We used antibodies against the Sm proteins, the trimethylguanosine cap found at the $5^{\prime}$ end of all snRNAs (except U6 snRNA; Lührmann 1988), and the U4/U6 snRNP protein PRP4 (Banroques and Abelson 1989; Petersen-Bjørn et al. 1989). The wild-type yeast U4 RNA present in each heterozygous strain provides a positive internal control. As shown in Figure 3, both mutant RNAs associate stably with the common core proteins, as indicated by their immunoprecipitability with anti$\mathrm{Sm}$ antibodies (lanes 2). They also precipitate with antibodies against the trimethylguanosine cap, suggesting that both mutants possess a correct cap structure (Fig. 3, lanes 1). In contrast, anti-PRP4 antibodies immunoprecipitate the U4-3'Tryp RNA (Fig. 3B, lane 3) (albeit in reduced amounts relative to wild-type U4; see below), whereas the U4ASL RNA is not immunoprecipitated by these antibodies (Fig. 3A, lane 3). This result suggests that the phylogenetically conserved 5 ' stem-loop structure of the yeast U4 RNA is essential for binding of the PRP4 protein. Immunoprecipitability of the U4ASL RNA and anti-PRP4 could not be restored by preincubation of extracts with ATP (data not shown).

The $5^{\prime}$ stem-loop of yeast U4 snRNA, but not the $3^{\prime}$ stem-loop, is dispensable for U4/U6 snRNP assembly

Although the experiments described above show that two of the three U4 mutant RNAs bind U4-associated proteins, they do not address the question of whether or not these U4 RNAs interact with the yeast U6 snRNA. It is known that the yeast U4/U6 snRNAs are stably as- 
Table 1. Properties of the yeast U4 mutant RNAs

\begin{tabular}{|c|c|c|c|c|c|c|c|c|}
\hline \multirow[b]{2}{*}{ Construct } & \multirow{2}{*}{$\begin{array}{l}\text { Deleted }(\Delta) \\
\text { or substituted }(S) \\
\text { U4 RNA nucleotides }\end{array}$} & \multirow[b]{2}{*}{ Length } & \multirow{2}{*}{$\begin{array}{l}\text { RNA } \\
\text { stability }\end{array}$} & \multirow{2}{*}{$\begin{array}{l}\text { Phenotype } \\
\text { on FOA }\end{array}$} & \multicolumn{2}{|c|}{ Immunoprecipitability by } & \multirow{2}{*}{$\begin{array}{l}\text { Association } \\
\text { with U6 } \\
\text { snRNA }\end{array}$} & \multirow{2}{*}{$\begin{array}{l}\text { Association } \\
\text { with U5 } \\
\text { snRNA }\end{array}$} \\
\hline & & & & & Anti-Sm & Anti-PRP4 & & \\
\hline $\mathrm{U} 4 \mathrm{wt}$ & - & 160 & yes & viable & yes & yes & yes & yes \\
\hline $\mathrm{U} 4 \Delta \mathrm{SL}$ & $\Delta 19-52$ & 127 & yes & lethal & yes & no & yes & no \\
\hline $\mathrm{U} 4 \Delta \mathrm{L}$ & $\Delta 31-43$ & 147 & no & lethal & - & - & - & - \\
\hline U4-3'Tryp & S $91-142$ & 119 & yes & lethal & yes & $\begin{array}{l}\text { yes (if associated } \\
\text { with U6 RNA) }\end{array}$ & yes $(30-40 \%)^{a}$ & yes \\
\hline & & & & & & no (if as free RNA) & no $(60-70 \%)$ & \\
\hline
\end{tabular}

The abbreviations used for the mutants are the same as those in Fig. 1. The predicted length of each mutant RNA is indicated in nucleotides.

'The U4-3'Tryp mutant RNA is found associated with U6 (30-40\% of the molecules) and as free RNA (60-70\%) (for more details, see text).

sociated in a complex with a melting temperature of $\sim 53^{\circ} \mathrm{C}$ (Brow and Guthrie 1988).

To determine whether the $\mathrm{U} 4$ mutants retain the ability to associate with the yeast U6 snRNA, we performed native gel electrophoresis by using proteinase $\mathrm{K} / \mathrm{SDS}$-treated extracts isolated from strains heterozy. gous for wild-type and mutant U4 genes. Because the U4ASL and U4-3'Tryp mutant RNAs differ in size from the wild-type U4 snRNA, we expected to be able to distinguish the U4 mutant/U6 complexes from the wildtype U4/U6 complex. The results of the native gel analysis are shown in Figure 4,A and B, where we observe a band corresponding to a complex with a mobility similar to the wild-type U4/U6 snRNAs. In addition, a second complex, with a greater mobility on the native gel, is seen for both U4ASL and U4-3'Tryp RNAs. In the case of the U4SSL mutant, incubation of the proteinase K/SDStreated extract at increasing temperatures results in the

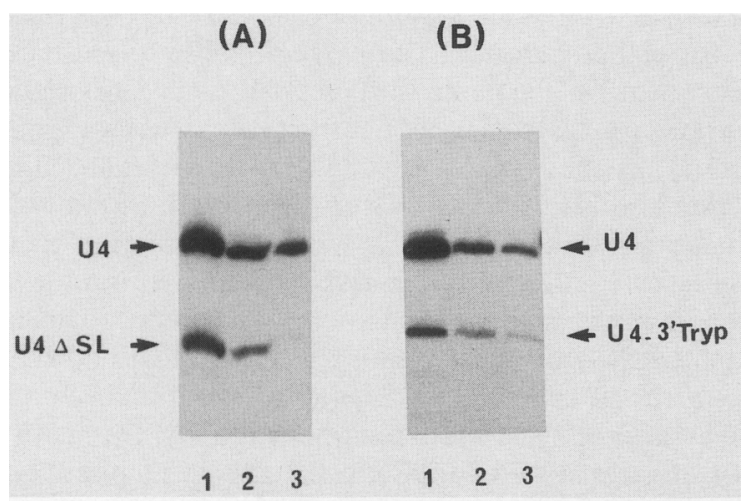

Figure 3. Immunoprecipitations of in-vivo-assembled $\mathrm{U} 4 \mathrm{mu}-$ tant snRNAs. Splicing extracts prepared from heterozygous strains RBU4ASL $(A)$ and RBU4-3'Tryp $(B)$ were immunoprecipitated, as described in Materials and methods with anti-trimethylguanosine (lane 1), anti-Sm (lane 2), and anti-PRP4 (lane 3) antibodies. All the washes were done at $150 \mathrm{~mm} \mathrm{NaCl}$. The precipitated RNAs were electrophoresed on a denaturing gel, transferred to nylon, and probed with ${ }^{32} \mathrm{P}$-labeled oligonucleotide $14 \mathrm{~B}(A)$ or $14 \mathrm{C}(B) . A$ and $B$ each represent independent electrophoresis. disappearance of the U4ASL/U6 complex and the simultaneous appearance of free U4DSL RNA (Fig. 4A). The melting temperature of the U4ASL/U6 complex is $\sim 55^{\circ} \mathrm{C}$, which is $2^{\circ} \mathrm{C}$ higher than that of the wild-type U4/U6 complex (Brow and Guthrie 1988). The fact that these melting temperatures are so similar suggests that both stem I and stem II are formed in the U4DSL/U6 complex, even in the absence of the $5^{\prime}$ stem-loop. Moreover, this experiment indicates that like the wild-type U4 RNA, the yeast U4ASL RNA is efficiently incorporated into a U4SSL/U6 complex. Thus, the phylogenetically conserved $5^{\prime}$ stem-loop of the yeast U4 snRNA is apparently dispensable for the formation of a stable U4/U6 complex.

The U4-3'Tryp mutant RNA is also able to associate with the U6 snRNA, as shown by the existence of a faster migrating complex in Figure $4 \mathrm{~B}$ (lanes $20-56^{\circ} \mathrm{C}$ ). This U4-3'Tryp/U6 complex has the same melting temperature as that of the wild-type counterpart $\left(53^{\circ} \mathrm{C}\right)$, suggesting that both complexes have similar stabilities. However, only $\sim 30-40 \%$ of the U4-3'Tryp RNA is associated with U6. Free U4-3'Tryp RNA is found after incubation of the proteinase K/SDS-treated extract even at low temperature, whereas no free wild-type U4 snRNA is produced until the incubation temperature reaches $56^{\circ} \mathrm{C}$. This result suggests that the highly divergent 3' stem-loop of the yeast U4 snRNA is important for the efficient formation of a U4/U6 complex. It should be pointed out, however, that the existence of free U4-3'Tryp RNA could be explained if this RNA folds into an alternative conformation that prevents its association with the yeast U6 snRNA. Alternatively, the $3^{\prime}$ stem-loop could represent a binding site for a specific protein that promotes complex formation.

\section{Fractionation of yeast snRNPs by glycerol gradient sedimentation}

We were concerned that association of mutant U4 snRNAs with wild-type U6 snRNA in extracts treated with proteinase $\mathrm{K}$ and SDS might be artifactual. Therefore, to determine the state of the mutant U4 snRNPs under more physiological conditions, we examined 


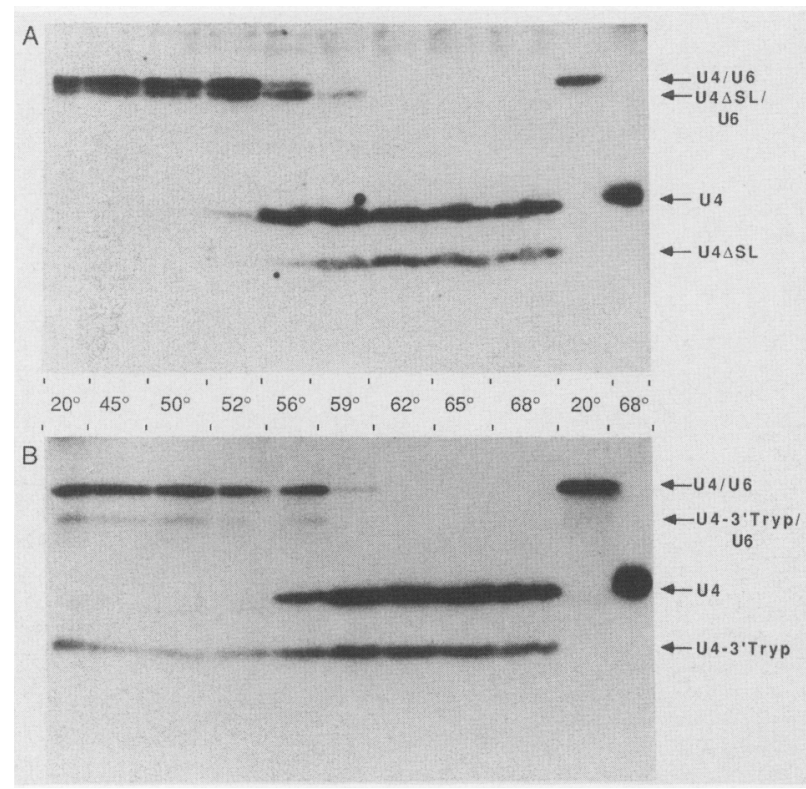

Figure 4. Association of the yeast U4 mutant snRNAs with the yeast U6 snRNA analyzed by native gel electrophoresis. Yeast whole cell extracts prepared from heterozygous strains RBU4 $\Delta S L(A)$ and RBU4-3'Tryp $(B)$ were treated with proteinase-K/SDS, as described in Materials and methods. After incubation of aliquots at the indicated temperatures, the samples were subjected to native polyacrylamide gel electrophoresis. After transfer, the blots were hybridized with a mixture of ${ }^{32} \mathrm{P}$ labeled oligonucleotides $14 \mathrm{~B}$ and $14 \mathrm{C}(B)$. The bands corresponding to the association of the wild-type and mutant U4 RNAs with the U6 RNA (U4/U6, U4ASL/U6, U4-3'Tryp/U6) and those corresponding to free U4 RNA species (U4, U4 $\Delta$ SL, U4-3'Tryp/are indicated at right. The two right-hand lanes in $A$ and $B$ represent RNA species present in the wild-type splicing extract isolated from strain KSY2 after incubation of the proteinase-K/SDS-treated aliquots at $20^{\circ} \mathrm{C}$ or $68^{\circ} \mathrm{C}$.

snRNP complexes in yeast splicing extracts by glycerol gradient sedimentation.

The existence of a single snRNP containing U4, U5, and U6 snRNAs has been reported both in yeast and mammals, but the behavior of this complex is different in both systems when the extracts are incubated with ATP: The yeast U4/U5/U6 snRNP dissociates upon ATP incubation (Cheng and Abelson 1987), whereas in HeLa cells, the amount of this snRNP increases in extracts incubated with ATP (Konarska and Sharp 1987; Black and Pinto 1989). Furthermore, Lossky et al. (1987) have shown that antibodies against the yeast U5 snRNP-specific protein PRP8 immunoprecipitate U5, U4, and U6 snRNAs only when the extracts are incubated with ATP. To investigate the effect of ATP on the tri-snRNP in our analysis, we incubated the yeast extracts for 30 min at $23^{\circ} \mathrm{C}$ in the absence or presence of $0.5 \mathrm{~mm}$ ATP and $20 \mathrm{~mm}$ creatine phosphate. These incubations were performed in the total absence of precursor RNA. Following centrifugation on a $10-30 \%$ glycerol gradient, the RNA of odd-numbered fractions was phenol-extracted and run on a denaturing polyacrylamide gel. After transfer to a nylon membrane, the blot was probed with labeled oligonucleotides complementary to U4, U5, and U6 RNAs. As shown in Figure 5A, incubation of the wild-type extract with ATP allows a clear separation of the snRNPs: Free U6 snRNP is found in fractions $15-19$, the U4/U6 snRNP sediments in fractions 9-13, and a multi-U4/U6/U5 snRNP migrates near the bottom of the gradient in fractions $1-5$. The identity of the snRNPs in these different fractions has been demonstrated by immunoprecipitation studies (see Figs. 6 and 7, below|. U5 sediments heterogeneously and is found in fractions 1-11. Such heterogeneity on glycerol gradient sedimentation has also been observed for the HeLa U5 snRNP (Bach et al. 1989). The yeast U5 snRNA exists as two species, U51 (217 nucleotides) and U5s (179 nucleotides), differing at their $3^{\prime}$ ends (Patterson and Guthrie 1987). As indicated in Figure 5A, both forms exhibit identical profiles when separated on a glycerol gradient.

When the wild-type extract is incubated without ATP (Figure 5B), the majority of the U4/U6 snRNP sediments as a U4/U5/U6 complex. These results indicate that upon ATP incubation, part of the yeast multi-U4/U5/U6 snRNP dissociates, generating a U4/U6 snRNP and a U5 snRNP (cf. Fig. 5A and Fig. 5B). This effect has been observed by use of different splicing extract preparations, although the amount of free U4/U6 particle in the extract without ATP incubation is variable. We have never observed an ATP dependence for the formation of the tri-U4/U5/U6 snRNP, as suggested by Lossky et al. (1987).

The 5' stem-loop of U4 snRNA is essential for the association of U4/U6 snRNP with the U5 SnRNP

The autoradiographs of the blots obtained by glycerol gradient separation of the extracts prepared from both mutant strains are shown in Figure 5C for strain RBU4DSL and Figure 5D for strain RBU4-3'Tryp. In contrast to the wild-type extract, an identical snRNP distribution has been observed after preincubation of these extracts with (data not shown) or without ATP (Figure $5 \mathrm{C}$ and D). In addition to the snRNPs found in the wildtype extract, the snRNA species corresponding to the yeast U4 mutant RNAs can clearly be identified. U4ASL snRNA is found in fractions 11-15 in extracts prepared from RBU4 $\Delta$ SL strain (Fig. 5C). This RNA is part of a U4 $\Delta S L /$ U6 particle (see below, Fig. 7), confirming that the U4ASL RNA associates stably with U6 snRNA in vivo. However, no U4ASL snRNA sediments at the bottom of the gradient, suggesting that the U4ASL/U6 is unable to associate with the U5 snRNP. Thus, the $5^{\prime}$ stem-loop of U4 appears to be absolutely required for the association of the U4/U6 snRNP with the U5 snRNP.

Figure 5D shows that a U4-3'Tryp/U6 snRNP, as well as a U4-3'Tryp/U5/U6 snRNP, sediments in fractions 11-13 and 3-5, respectively. Interestingly, we can also clearly identify a U4-3'Tryp snRNA species (fractions 17-19) sedimenting at a value similar to the free U6 


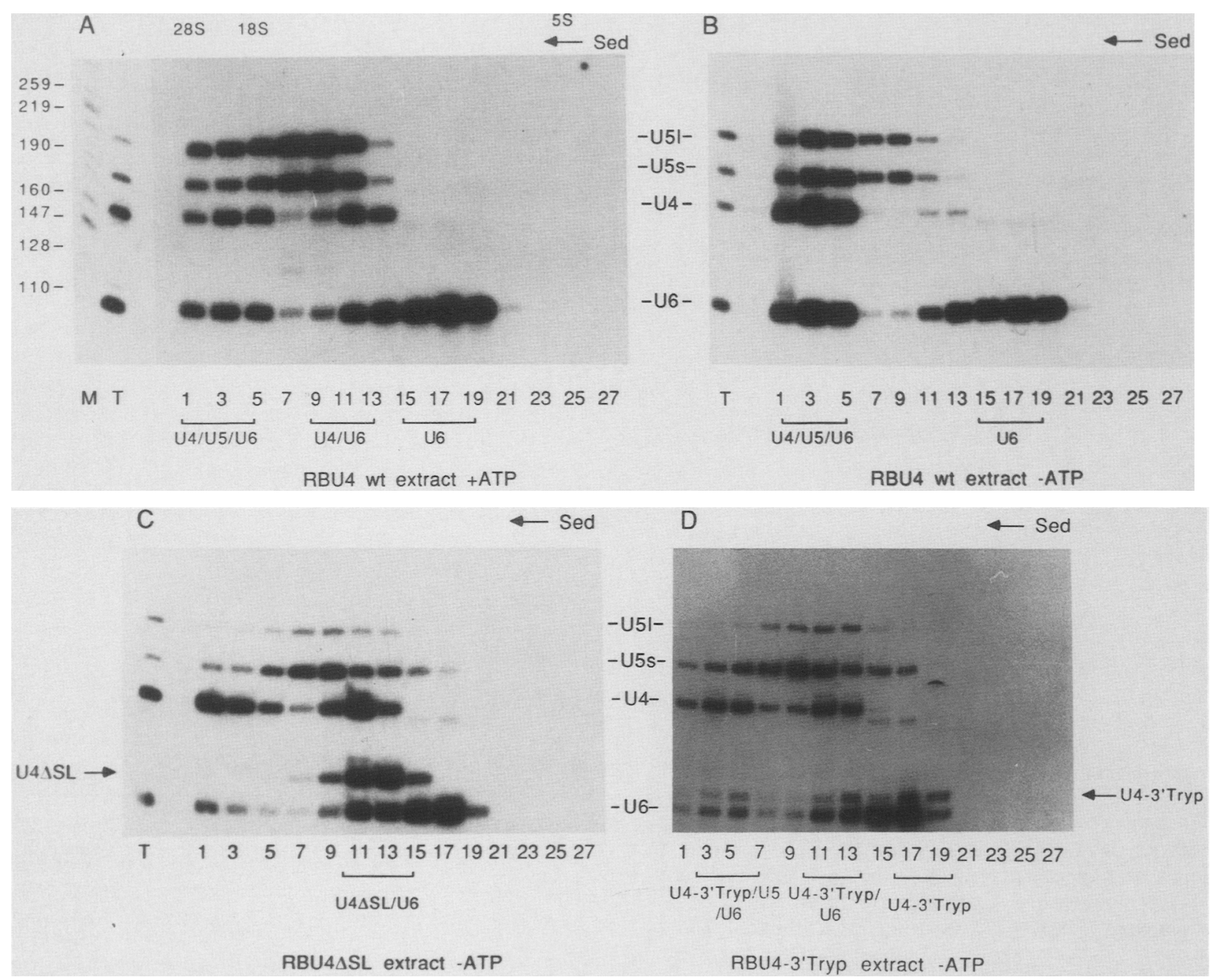

Figure 5. Glycerol gradient sedimentation of yeast snRNPs. Splicing extracts were incubated with or without ATP and subjected to glycerol gradient sedimentation, as described in Materials and methods. The RNAs were then transferred to a nylon membrane for Northern blot analysis. Autoradiographs of such blots are shown. The blots in $A$ and $B$ were probed with a mixture of oligonucleotides 14C, 6B, and 7wtSmNR (see Materials and methods); the blots in $C$ and $D$ were probed with a mixture of oligonucleotides 14B, 14C, 6B, and 7wtSmNR. (A) Wild-type extract prepared from the RBU4wt strain incubated with $2 \mathrm{mM} \mathrm{MgCl}_{2}, 0.5 \mathrm{mM} \mathrm{ATP}$ and $20 \mathrm{~mm}$ creatine phosphate. $(B)$ Wild-type extract incubated without ATP. $|C|$ Extract prepared from heterozygous strain RBU4 $\Delta S L$ incubated without ATP. $(D)$ Extract from heterozygous strain RBU4-3'Tryp incubated without ATP. Concerning the mutant strains, similar patterns were obtained when the extracts were incubated with ATP and creatine phosphate (see text). (T) Phenol-extracted total RNA from the wild-type strain RBU4wt. Molecular-weight markers (M) are 5'-end-labeled pBR325 HpaII fragments. The direction of sedimentation is top to bottom, as indicated by the arrow. The fraction numbers of each gradient and the positions of the different snRNP complexes are shown at the bottom. For the mutant extracts, only the complexes containing the mutant U4 snRNA are indicated. The RNA species and the sedimentation values for phenol-extracted 5S, 18S, and 28S S. cerevisiae rRNA used as standard are indicated. Note that the autoradiograph represented in $D$ is a light exposure of the blot to distinguish the U4-3'Tryp and the U6 snRNA species. The additional weak band found in fractions $15-17$ in $B, C$, and $D$ represents RNA that hybridizes with the U4 probes and might correspond to specifically degraded U4 RNA unable to bind U6.

snRNP. As shown by immunoprecipitation experiments (see below), this U4-3'Tryp snRNA is complexed with the common core proteins but is not associated with U6 snRNA. Both snRNA species in fractions $17-19$ are complexed with proteins, because phenol-extracted U4 and U6 snRNAs migrate in fractions $23-25$ in a $10-30 \%$ glycerol gradient (data not shown).
In summary, these results corroborate the data obtained by native gel analysis and show that (1) the highly phylogenetically conserved $5^{\prime}$ stem-loop in yeast $\mathrm{U} 4$ is dispensable for the formation of a U4/U6 snRNP; (2) this domain is required for the association of U4/U6 snRNP with the U5 snRNP; (3) the $3^{\prime}$ stem-loop is important for efficient formation of U4/U6 snRNPs. 


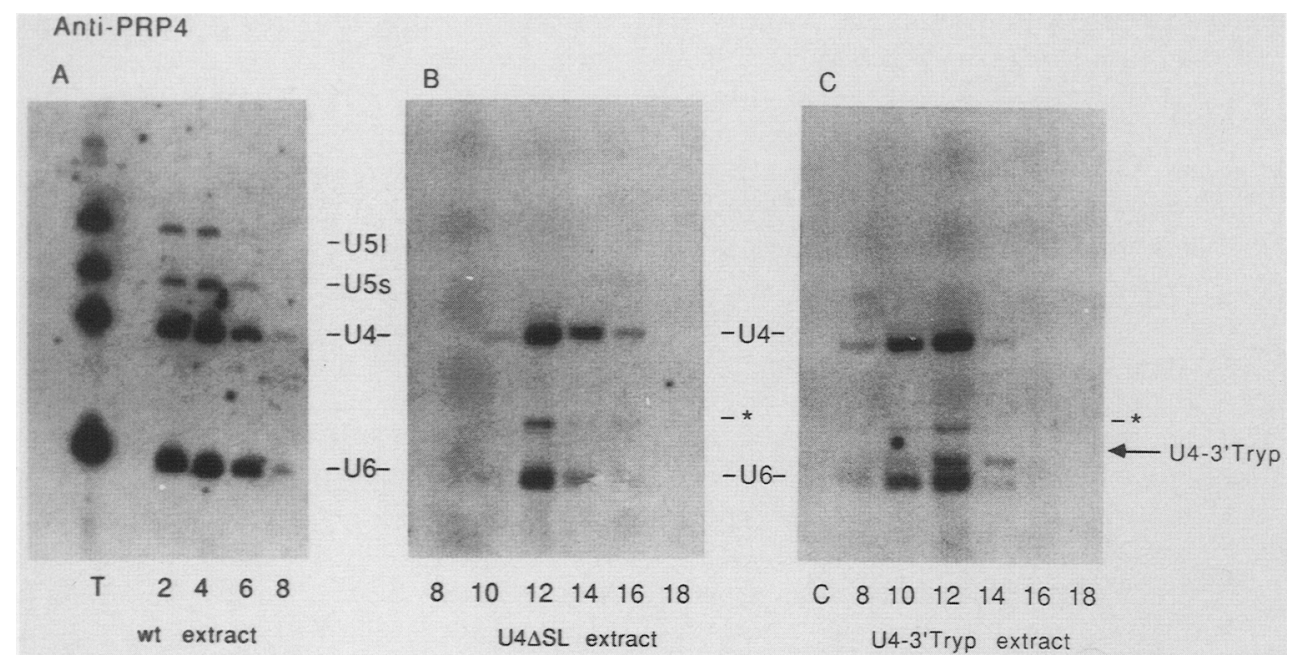

Figure 6. Immunoprecipitation of individual snRNPs with anti-PRP4 antibodies. Immunoprecipitations were performed by use of the fractions separated on glycerol gradients shown in Fig. 5. After incubation of the fractions with PRP4 antibodies, as described in Materials and methods, the precipitated RNA was subjected to Northern blot analysis. Autoradiographs of the blots are shown. $(A)$ Fractions 2-8 of the gradient shown in Fig $5 \mathrm{~A}_{;}(B)$ fractions $8-18$ of the gradient shown in Fig. $5 \mathrm{C} ;(C)$ fractions $8-18$ of the gradient shown in Fig. 5D. The names of the extracts, from which the fractions are generated, are indicated at bottom. As a control of the specificity of PRP4 antibodies, total extract of strain RBU4wt was immunoprecipitated with preimmune serum (lane C in $C$ ). The asterisks $\left(^{*}\right)$ in $B$ and $C$ indicate a band corresponding to a degradation product of the wild-type U4 snRNA.

\section{Immunoprecipitation analysis of individual snRNPs}

To confirm the identity of the snRNPs present in each fraction of the glycerol gradient and to investigate the protein composition of individual snRNPs, we performed immunoprecipitation studies by using anti-Sm and anti-PRP4 antibodies. The RNPs present in fractions $2,4,6$, and 8 [corresponding to the sedimentation of the wild-type extract (gradient shown in Fig. 5A)] were immunoprecipitated with anti-PRP4, and the RNA was extracted and analyzed by Northern blotting. As shown in

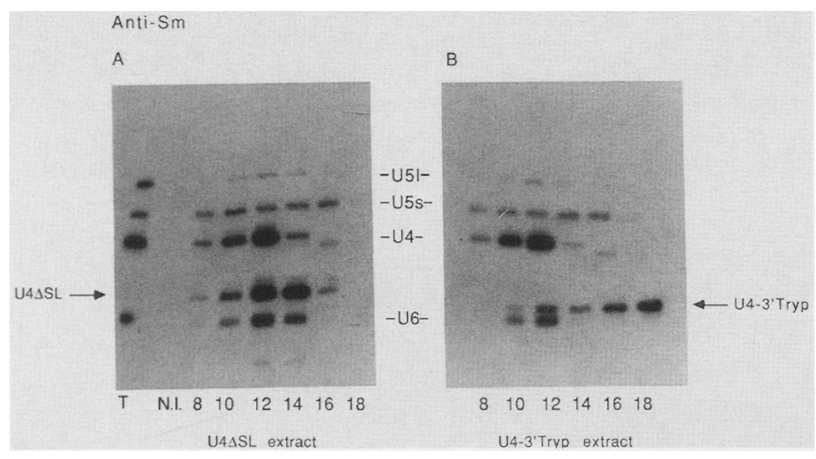

Figure 7. Immunoprecipitation of individual snRNPs with anti-Sm antibodies. Fractions $8-18$ of a gradient equivalent to that shown in Fig. 5C $(A$; RBU4 $\Delta$ SL extract $)$ and fractions 8-18 of a gradient equivalent to that shown in Fig. 5D $(B$; RBU4-3'Tryp extract) were immunoprecipitated with Sm antibodies, and the RNA was subjected to Northern analysis. Autoradiographs of the blots are shown. (N.I.) Nonimmune human serum incubated with total extract of strain RBU4wt.
Figure 6A, U4, U5, and U6 snRNAs in fractions 2, 4, and 6 are immunoprecipitated with anti-PRP4, demonstrating unambiguously that the snRNP migrating at the bottom of the gradient corresponds to the multi-U4/U5/ U6 snRNP. Indeed, previous observations suggested that anti-PRP4 precipitates U5 snRNA at low salt conditions only when this RNA is associated with the U4/U6 snRNP (Banroques and Abelson 1989; Petersen-Bjørn et al. 1989). This is confirmed by our immunoprecipitation experiments when fractions $8-18$ from similar gradients to those shown in Figure 5,C and D, are used. Neither form of U5 snRNP present in fractions $8-18$ precipitates with anti-PRP4, whereas the U4/U6 snRNAs in fractions 12-14 are precipitated (Fig. 6B and C). These results demonstrate that those fractions contain the $\mathrm{U} 4 / \mathrm{U} 6 \mathrm{snRNP}$ and, in addition, prove directly that PRP4 is a component of the U4/U6 snRNP but not of free U5 snRNP. These experiments also show that the U6 snRNP found in fractions $16-18$ is not precipitated by anti-PRP4 antibodies (Fig. 6B and Cl, indicating that PRP4 is not a U6-specific protein. The specificity of the immunoprecipitations with anti-PRP4 antibodies has been demonstrated previously (Banroques and Abelson 1989 ) but is confirmed by the absence of signals from preimmune serum (lane $\mathrm{C}$ in Fig. $6 \mathrm{C}$ ).

The identity of snRNPs in the glycerol gradient fractions is further confirmed by our immunoprecipitation experiments with anti-Sm antibodies. As shown in Figure 7, A and B, the U6 snRNA is precipitated only when it is associated with U4 snRNA (fractions 10-14), whereas U6 snRNA in fractions $16-18$ is not precipitated by these antibodies. In contrast, both U5 RNA forms are precipitated with anti-Sm in all fractions. 
For the mutant U4 RNAs, the immunoprecipitation experiments show that the U4-3'Tryp RNA species is precipitated by anti-PRP4 antibodies only when complexed with U6 snRNA (fractions 10 and 12 in Fig. 6C) but not when it is free (Fig 6C, fractions 16 and 18). However, the U4-3'Tryp RNA species is precipitated with anti-Sm antibodies (Fig. 7B, fractions 16 and 18). Likewise, the U4 $\Delta S L$ binds the common core proteins, as shown by its immunoprecipitability with anti-Sm antibodies (Fig. 7A, fractions 12 and 14) but, in contrast to the U4-3'Tryp RNA, is not precipitated with anti-PRP4 antibodies (Fig. 6B, fractions 12-16). The properties of the U4 mutant RNAs are summarized in Table 1.

Taken in combination, our results indicate that the conserved $5^{\prime}$ stem-loop of yeast $\mathrm{U} 4$ is essential for binding of the PRP4 protein but is not sufficient because free U4-3'Tryp, which still retains this domain, cannot bind this protein. However, when the U4-3'Tryp RNA is complexed with U6 snRNA, it is immunoprecipitated by anti-PRP4, suggesting that U4/U6 association is necessary for PRP4 binding to U4 snRNA. This may reflect direct interactions between PRP4 and U6 sequences or an indirect effect because U6 could be needed to allow the formation of the conserved U4 5' stem-loop. Our experiments do not distinguish whether or not PRP4 binds directly to this stem-loop.

\section{Discussion}

By using deletion and substitution mutants, we have shown that the $5^{\prime}$ and $3^{\prime}$ stem-loops of $S$. cerevisiae U4 snRNA are essential for the assembly of a functional U4/U6 snRNP in vivo. The U4ASL and U4-3'Tryp mutant snRNAs described in this study are unable to complement a wild-type gene disruption, but they are incorporated into stable snRNPs. Native gel electrophoresis, glycerol gradient centrifugation, and immunoprecipitation studies allowed us to show that these mutants are defective in interactions of the U4 snRNA with other components of the spliceosome.

\section{Distribution of U4/U6 and U5 snRNPs in glycerol gradients}

This is the first report of the fractionation of yeast snRNPs by glycerol gradient centrifugation. As shown in Figure 5, the U4/U5/U6 snRNP, U4/U6 snRNP, and U6 snRNP are clearly resolved under our experimental conditions. No clear separation of the yeast U1 and U2 snRNPs, which migrate in fractions $1-7$ of the gradient, was obtained (data not shown). Our study shows that a portion of the U4/U5/U6 snRNP complex dissociates upon incubation of a wild-type extract in the presence of ATP to give U4/U6 snRNP and a free U5 particle (Fig. $5 \mathrm{~A}$ and $\mathrm{B} \mid$. As already mentioned in the results, an ATPdriven dissociation of the U4/U5/U6 snRNP has also been observed in $S$. cerevisiae whole cell extract when analyzed by native gel electrophoresis (Cheng and Abelson 1987). The observation of ATP-dependent dissociation of the U4/U5/U6 snRNP in yeast extracts is dif- ferent from that reported for the HeLa U4/U5/U6 particle. Indeed, in HeLa cells, the interaction of the U5 snRNP with the U4/U6 snRNP is ATP-dependent (Konarska and Sharp 1987; Black and Pinto 1989). Such an ATP-dependent interaction of U4 and U6 snRNAs with the U5 snRNA is also observed in yeast extracts in immunoprecipitation experiments with antibodies against the U5 snRNP-specific protein PRP8 (Lossky et al. 1987). Thus, although our glycerol gradients contained low salt ( 25 or $50 \mathrm{~mm} \mathrm{NaCl}$ ) compared to those of Black and Pinto $(1989 ; 100 \mathrm{~mm} \mathrm{KCl})$ it seems unlikely that the observed differences of the ATP effect on the multi-U4/ U5/U6 snRNP in yeast and HeLa extracts are simply due to differences in salt concentration. This is supported by the finding that this particle is remarkably stable under a wide range of $\mathrm{pH}$, temperature, and salt conditions (Konarska and Sharp 1987, 1988).

It is interesting to note that no effect is observed upon ATP incubation on the dissociation of the wild-type U4/U5/U6 particle present in the extracts isolated from the mutant strains: Without (Fig. 5C and D) or with ATP (data not shown), the same amount of the multi-snRNP and free U4/U6 particle is always found. This may be due to the fact that the mutant particles compete with the wild-type U4/U6 snRNP for limiting factors that are required for the association of the U4/U6 complex with the U5 snRNP. Such factors could be sequestered by the mutant U4/U6 snRNAs and therefore no longer be available for interaction with the wild-type U4/U6 snRNP. However, no dominant inhibitory effect of the mutant U4 snRNAs on growth of the heterozygous strains has been observed, suggesting that the effective concentration of wild-type U4/U5/U6 snRNP is not limiting for growth. We do not know whether the U4 mutants have an inhibitory effect on in vitro splicing because we were not able to obtain active splicing extracts from the heterozygous strains; this failure may be explained by the fact that these strains have to be grown in minimal synthetic medium to maintain the mutant genes. In any event, the putative limiting factor is unlikely to be PRP4, because the U4ASL/U6 snRNP lacks this protein (see below).

\section{Structural requirements for U4/U6 snRNP formation}

By oligonucleotide-directed cleavage using RNase $\mathrm{H}$, it has been shown that the region of U4 snRNA which is the most accessible for targeted degradation, is the single-stranded sequence located between stem I and the $3^{\prime}$-terminal domain, both in yeast (Xu et al. 1990) and in mammals (Berget and Robberson 1986; Black and Steitz 1986). Other regions of the U4 snRNA, such as the $5^{\prime}$ stem-loop and the 3 '-terminal domain, become accessible to nuclease digestion only after phenol extraction, suggesting that these regions are complexed with proteins (Black and Steitz 1986; Lehay-Taha et al. 1986; Xu et al. 1990). This is consistent with our findings. The failure of the U4DSL/U6 particle to be immunoprecipitated by anti-PRP4 antibodies (Figs. 3 and 6B) demon- 
strates that the conserved $5^{\prime}$ stem-loop of yeast U4 snRNA is an essential determinant for the binding of the PRP4 protein. This result is in agreement with the recent report of $\mathrm{Xu}$ et al. (1990), showing that the $5^{\prime}$ portion of U4 snRNA (nucleotides $1-65$ ) and the $3^{\prime}$ portion of U6 snRNA ( $\sim 50$ nucleotides) coimmunoprecipitate with the PRP4 protein.

Our results further demonstrate that the $5^{\prime}$ stem-loop of U4 snRNA is dispensable for the formation of a stable U4/U6 snRNP. Interestingly, the melting temperature of the $\mathrm{U} 4 \Delta \mathrm{SL} / \mathrm{U} 6$ complex is $2^{\circ} \mathrm{C}$ higher than that of the wild-type U4/U6 particle. The normal U4/U6 RNA base-pairing interaction is interrupted (in U4) by a bulge loop and an intramolecular hairpin, whereas the mutant duplex is interrupted only by the bulge loop (see Fig. 1). Previous studies determining the thermodynamic stability of model oligonucleotides indicated that the disruption of an RNA duplex by a 4-nucleotide bulge loop can result in a free-energy increment of $6.4 \mathrm{kcal} /$ mole (for RNA at $37^{\circ} \mathrm{C}$ in $1 \mathrm{M} \mathrm{NaCl}$; Freier et al. 1986). The contribution of an intramolecular helix has not been reported. Our observations suggest that the additional introduction of this structure in wild-type $\mathrm{U} 4$ is more destabilizing than is the bulge loop alone.

Although the 5' stem-loop of U4 snRNA is dispensable for efficient formation of a stable U4/U6 snRNP, our results show that the presence of the hairpin is a prerequisite for function. The structure of this region of U4 snRNA is highly conserved from yeast to mammals: The 17 -nucleotide loop is $76 \%$ conserved in sequence, but all 13 nucleotides comprising the central stem change identity (Brow and Guthrie 1988). Whether or not this structure comprises a direct binding site of PRP4 cannot be assessed by our study. Nevertheless, the conservation of the loop sequence during evolution, together with the RNase $\mathrm{H}$ experiments described above, makes this loop a good candidate for a protein-binding site.

Are other RNA-protein interactions also required for the binding of the PRP4 protein to the U4/U6 particle? This possibility is raised by the finding that U4-3'Tryp mutant, which still contains the $5^{\prime}$ stem-loop domain, only binds PRP4 when U6 snRNA is bound to it. That is, a significant percentage of the $3^{\prime}$ stem-loop mutant RNA is found free of U6 and is not immunoprecipitated by anti-PRP4 antibodies (Fig. 6C). It has been shown recently that binding of PRP4 to the U4/U6 snRNP induces a weak protection from nuclease digestion of the U6 sequences in stem I and stem II (Xu et al. 1990). Taken together, these results suggest that the intermolecular helices that are formed when the U4 and U6 snRNAs are base-paired together may comprise an additional determinant for PRP4 binding. Alternatively, these helices may simply promote formation of the U4 5 ' stem-loop. Finally, binding of PRP4 could require interactions with another specific U4 and/or U6 protein. A candidate for such a protein could be PRP3, because a defective prp4 gene can be complemented by extra copies of the PRP3 gene (Last et al. 1987), suggesting that PRP4 and PRP3 may function in a related way. Further studies will be needed to define precisely the binding site(s) of PRP4 in the U4/U6 snRNA.

A second, putative protein-binding site is implicated by our study, the $3^{\prime}$ stem-loop of yeast U4 snRNA. This region can be folded into a stem-loop in all organisms; however, its structure exhibits large phylogenetic variation in size and sequence (Guthrie and Patterson 1988). In the yeasts $S$. cerevisiae and Kluyveromyces lactis, this $3^{\prime}$ portion forms a helix containing $18 \mathrm{bp}$, whereas in $T$. brucei, the stem consists of only $3 \mathrm{bp}$. The Smbinding site is located $3^{\prime}$ to this stem-loop in all U4 snRNAs. In all organisms except $S$. cerevisiae and $K$. lactis, the Sm-binding site is followed by a second stem-loop (Guthrie and Patterson 1988).

The swap of the $3^{\prime}$ stem-loop in yeast U4 snRNA with the corresponding domain of the trypanosome U4 RNA does not affect the binding of the common core proteins (Figs. 3 and 7). However, only $30-40 \%$ of the U4-3'Tryp RNA is assembled into a U4-3'Tryp/U6 snRNP complex, as shown by native gel electrophoresis and glycerol gradient sedimentation. One explanation of this result is that $60-70 \%$ of the U4-3'Tryp mutant RNA molecules fold into an alternate conformation that does not allow the formation of stem I and stem II with U6 snRNA. This hypothesis is supported by our results, showing that the U4-3'Tryp snRNA species sedimenting at the top of the glycerol gradient can be immunoprecipitated by the anti-Sm antibodies but not by anti-PRP4 antibodies (Figs. 6C and 7B), suggesting that the PRP4binding site is destroyed in this RNA. One role of the U4 3 '-terminal domain might therefore be to prevent the formation of a competing structure in the $5^{\prime}$ region of the U4 snRNA. Alternatively, a protein that binds to the 3 ' stem-loop of yeast U4 snRNA might directly promote the association of U4 and U6 snRNAs. Interactions between such a protein and a U6-specific protein, or the U6 snRNA itself, might also serve to stabilize the U4/U6 RNA interaction, though we note that the melting temperature of the mutant complex that does form is equivalent to that of wild type in our assays. In this regard, it is interesting to note that by probing the U4/U6 snRNP with 2'-OMe RNA oligonucleotides, Blencowe et al. (1989) recently argued that the base pairs in stem II are disrupted as spliceosome assembly proceeds, although the U4 and U6 snRNAs remain associated in a complex. These investigators proposed that stem II forms transiently during spliceosome assembly and suggested that U4 RNA does not leave the spliceosome but, rather, is subject to a conformational change that impairs its association with the U6 RNA in the stem II region. Accordingly, the putative protein that binds to the $3^{\prime}$ stem-loop could serve to stabilize the U4/U6 complex in the absence of base-pairing in stem II. The loss of this protein in the U4-3'Tryp mutant would thus have two consequences. In addition to reducing the total amount of the U4/U6 snRNP, the function of the mutant complexes that are formed would be impaired in splicing following the disruption of stem II. Such a model could explain the failure of the U4-3'Tryp mutant to complement a null allele of the U4 gene, despite the 
fact that it still forms a substantial amount of U4-3'Tryp/U5/U6 particle (Fig. 5D).

\section{Role of the PRP4 protein}

The existence of the U4/U5/U6 snRNP has been shown previously by glycerol gradient analysis and native gel electrophoresis of splicing complexes (Cheng and Abelson 1987; Konarska and Sharp 1987, 1988). These studies led to models for spliceosome assembly in which the U4/U6 snRNP is brought to the spliceosome by the interaction with the U5 snRNP. The involvement of the U4/U6 snRNP in an early step in the splicing process was inferred by experiments with oligonucleotide/ RNase-H-directed cleavage of U4 and U6 snRNAs (Berget and Robberson 1986; Black and Steitz 1986). Indeed, degradation of both snRNAs inhibits the initial cleavage step. An early role for PRP4 in the splicing reaction has also been demonstrated by use of antibody inhibition experiments (Banroques and Abelson 1989). In these studies, depletion of the snRNPs associated with PRP4 by anti-PRP4 antibodies resulted in an accumulation of complex B [which contains the pre-mRNA and the U2 snRNP (Cheng and Abelson 1987)] and inhibition of the formation of the later complexes.

Our study suggests that the association of the U4/U6 snRNP with the U5 snRNP is likely to be an obligate step in the pathway leading to the formation of an active splicing complex in vivo. This is based on the observation that the U4ASL/U6 snRNP is unable to associate with the U5 snRNP and fails to support splicing. Because PRP4 does not bind to the U4SSL/U6 snRNP, these results also suggest that the PRP4 protein is required for the association of the U4/U6 snRNP with the U5 snRNP. How is the association between these snRNPs mediated? Interestingly, Dalrymple et al. (1989) reported recently that the PRP4 protein contains five repeated amino acid segments that are found in the $\beta$-subunits of the G protein family. These workers proposed that these motifs might play a general role in proteinprotein interactions. Conceivably, then, the $\mathrm{G}$ motifs found in PRP4 may be responsible for interaction with a specific U5 snRNP protein. Further genetic studies of the U4/U5/U6 snRNP formation pathway, as well as biochemical analyses of the purified PRP4 protein, will be required for a better understanding of the role of the PRP4 protein and the function, if any, of the conserved G motifs.

\section{Materials and methods}

\section{Strain and media}

The haploid strain KSY2 (MATa trp1 his3 ura3 ade2 lys2 snr14 :: TRP1) carries a disrupted chromosomal copy of the SNR14 gene, which is complemented by the wild-type SNR14 gene on a YCp50 vector (CEN ARS1 URA3). This strain was kindly provided by Karen Shannon (University of California, San Francisco). YEPD, - His (synthetic media lacking histidine) were prepared as described by Sherman et al. (1974).

\section{Plasmid construction and mutagenesis}

A 0.56-kb EcoRI-BamHI subclone containing the SNR14 gene (Siliciano et al. 1987) was cloned into the EcoRI-BamHI site of Bluescript $\mid+1$. Preparation of single-stranded DNA and oligonucleotide mutagenesis was performed by use of the $d u t^{-} u^{-}$ technique (Kunkel et al. 1987), as described by McClary et al. (1989). The EcoRI-BamHI DNA fragments containing the wild-type $\mathrm{U} 4$ gene, the deletion mutants $\mathrm{U} 4 \Delta \mathrm{SL}$ and $\mathrm{U} 4 \Delta \mathrm{L}$, and the substitution mutant U4-3'Tryp were subcloned into the pKE362 vector (CEN ARS1 HIS3; derived from pUN90; Elledge and Davis 1988) to yield pyU4wt, pyU4 $\Delta S L$, pyU4 $\Delta L$, and pyU4-3'Tryp, respectively. The sequence of each construct was confirmed by dideoxynucleotide sequencing with Sequenase (U.S. Biochemicals).

\section{Plasmid shuffle assay}

Yeast transformations were performed by the method of Ito et al. (1983), and the transformants selected on -His plates. The haploid strains obtained by transformation of KSY2 with pyU4wt, pyU4 $\Delta \mathrm{SL}$, pyU4 $4 \mathrm{~L}$, and pyU4-3'Tryp were named RBU4wt, RBU4ASL, RBU4AL, and RBU4-3'Tryp, respectively. The phenotypes of these strains were determined by use of the plasmid shuffle method (Boeke et al. 1987). Three independent colonies were streaked onto plates lacking tryptophan (to select for the SNR14 gene disruption) and containing $0.75 \mathrm{mg} / \mathrm{ml}$ FOA. The viability of the strains was checked after several days of incubation at $18,25,30$, and $37^{\circ} \mathrm{C}$. Because FOA selects for cells that have lost a functional $U R A 3$ gene, the phenotype of strains on the FOA plates will be due to the U4 mutant genes carried by the pKE362 vector. The RBU4wt strain, carrying a wild-type U4 gene on the pKE362 vector, was used as a positive control. KSY2 strain (carrying a wild-type U4 gene on a URA3 vector|, transformed with pKE362 vector alone, was used as a negative control.

\section{Yeast extract preparation}

The heterozygous haploid strains RBU4 $\Delta$ SL and RBU4-3'Tryp, as well as the wild-type strain RBU4wt, were grown to $\mathrm{OD}_{600}=$ 4 in 2 liters of synthetic medium lacking histidine, tryptophan, and uracil. The yeast whole cell extract was prepared according to Lin et al. (1985).

\section{Native gel electrophoresis of U4/U6 SnRNA}

The formation of a complex between the mutant U4 snRNAs and U6 snRNA was determined by native gel electrophoresis by use of the method described by Brow and Guthrie (1988), with some minor modifications. Yeast whole cell extract $(70 \mu \mathrm{l})$ was treated with proteinase $\mathrm{K}$ in a total volume of $100 \mu \mathrm{l}$ in a buffer containing $40 \mathrm{~mm}$ Tris-Cl (pH 7.4), $140 \mathrm{~mm} \mathrm{NaCl}, 2 \%$ SDS, and $2 \mathrm{mg} / \mathrm{ml}$ proteinase $\mathrm{K}$. After incubation at $20^{\circ} \mathrm{C}$ for $30 \mathrm{~min}$, the mixture was diluted to $500 \mu$ l in the same buffer without proteinase $\mathrm{K}$. Aliquots $(50 \mu \mathrm{l})$ were incubated for $5 \mathrm{~min}$ at the temperatures indicated in Figure 4, returned to $20^{\circ} \mathrm{C}$, and mixed with $10 \mu$ l of loading buffer (50\% glycerol, $0.02 \%$ bromphenol blue). The samples were then loaded immediately on a $3-8 \%$ polyacrylamide discontinuous native gel (Brow and Geiduschek 1987). Electrophoresis and transfer to HyBond $\mathrm{N}$ membrane was as described by Brow and Guthrie (1988). Hybridization of the blots was performed as indicated below.

\section{Glycerol gradient sedimentation analysis}

Before centrifugation, the yeast extracts $(75 \mu \mathrm{l})$ were preincubated without pre-mRNA for $30 \mathrm{~min}$ at $23^{\circ} \mathrm{C}$ with or without 2 
$\mathrm{mm} \mathrm{MgCl}_{2}, 0.5 \mathrm{~mm}$ ATP and $20 \mathrm{~mm}$ creatine phosphate. The mixtures were then diluted threefold with buffer A $150 \mathrm{mM}$ Tris-Cl ( $\mathrm{pH} 7.4), 25 \mathrm{~mm} \mathrm{NaCl}, 5 \mathrm{mM} \mathrm{MgCl}_{2}$ ) and layered on 11 $\mathrm{ml} 10-30 \%$ (wt/vol) glycerol gradients in buffer A. After sedimentation at $37,000 \mathrm{rpm}$ for $14 \mathrm{hr}$ in a SW41 rotor at $4^{\circ} \mathrm{C}$, fractions of $400 \mu \mathrm{l}$ were recovered. Odd-numbered fractions were extracted with an equal volume of phenol chloroform, ethanolprecipitated, and resuspended in $10 \mu$ l of loading buffer $199 \%$ formamide, $0.02 \%$ xylene cyanol, $0.02 \%$ bromphenol blue). The RNA samples were then subjected to Northern analysis as described below.

\section{Immunoprecipitations}

Anti-Sm (Pettersson et al. 1984) and anti-trimethylguanosine antibodies were generous gifts from J. Steitz and R. Lührmann. Anti-PRP4 antibody has been described and characterized previously (Banroques and Abelson 1989). Immunoprecipitations with total splicing extract were performed as described by Banroques and Abelson (1989). Immunoprecipitations of the RNA present in the glycerol gradient fractions were performed according to Hamm et al. (1987), as follows. Antiserum $(2 \mu \mathrm{l}$ anti-Sm or $10 \mu \mathrm{l}$ anti-PRP4) was coupled to $40 \mu \mathrm{l}$ protein ASepharose (Pharmacia; $0.1 \mathrm{~g} / \mathrm{ml}$ of buffer B) in $500 \mu l$ of buffer B [50 mM Tris-Cl (pH 7.4), $150 \mathrm{mM} \mathrm{NaCl}, 5 \mathrm{~mm} \mathrm{MgCl}_{2}, 0.1 \%$ Nonidet $\mathrm{P}-40$, and $0.1 \%$ sodium azide] for $90 \mathrm{~min}$ at $4^{\circ} \mathrm{C}$. The beads were washed three times with $1 \mathrm{ml}$ of the same buffer. Glycerol gradient fraction $(400 \mu \mathrm{l})$ was added to the antibodybound protein $\mathrm{A}-$ Sepharose and rolled for $90 \mathrm{~min}$ at $4^{\circ} \mathrm{C}$. The resin was washed three times with $1 \mathrm{ml}$ of buffer B and phenolchloroform-extracted, and the RNA was ethanol-precipitated. The RNA samples were then subjected to Northern analysis.

\section{Northern blot analysis}

Total yeast RNA was isolated by the guanidinium thiocyanate method as described by Wise et al. (1983). RNA samples were separated on a $6 \%$ polyacrylamide $/ 7 \mathrm{M}$ urea denaturing gel and transferred electrophoretically to HyBond $\mathrm{N}$ membrane in 20 $\mathrm{mM} \mathrm{NaPO}_{4}\left(\mathrm{pH} 6.5\right.$ ) at $7 \mathrm{~V}$ for $15 \mathrm{hr}$ at $4^{\circ} \mathrm{C}$. After UV treatment, the membrane was prehybridized for $1 \mathrm{hr}$ in $6 \times$ SSC, $5 \times$ Denhart's solution, and $0.2 \%$ SDS at $65^{\circ} \mathrm{C}$. Hybridization was performed at room temperature in the same solution with $1 \times 10^{6}$ Cerenkov counts per milliliter of $5^{\prime}$-end-labeled oligonucleotide. Filters were washed twice for $5 \mathrm{~min}$ at $37^{\circ} \mathrm{C}$ in $6 \times \mathrm{SSC}$ and $0.2 \%$ SDS. The following oligonucleotides were used as probes: 14C (5'-CACAATCTCGGACGAATCCTC) complementary to residues $32-52$ of yeast U4 snRNA; 14B $15^{\prime}$-AGGTATTCCAAAAATTCCCTAC) complementary to residues 137-158 of yeast U4 snRNA; 6B (5'-TCATCCTTATGCAGGG) complementary to residues $67-82$ of yeast U6 snRNA; $7 \mathrm{wtSmNR}$ (5'AAGTTCCAAAAAATATGGCAAGC) complementary to residues 158-180 of yeast U5 snRNA (Patterson and Guthrie 1987).

\section{Acknowledgments}

We thank the members of the Guthrie laboratory for materials and many useful discussions. We are grateful to David Brow, Dan Frank, Hiten Madhani, and Karen Shannon for their helpful comments on the manuscript. We also thank Lucita Esperas for technical assistance. This work was supported by grants from the National Institutes of Health (NIH; GM-21119) and the National Science Foundation (DMB8603926) to C.G. and by a grant from the NIH (GM32637) to J.A. R.B. was the recipient of a Fogarty International Fellowship [Centre National de la Recherche Scientifique (CNRS)/NIH program].

The publication costs of this article were defrayed in part by payment of page charges. This article must therefore be hereby marked "advertisement" in accordance with 18 USC section 1734 solely to indicate this fact.

\section{References}

Bach, M., G. Winkelmann, and R. Lührmann. 1989. 20S small nuclear ribonucleoprotein U5 shows a surprisingly complex protein composition. Proc. Natl. Acad. Sci. 86: 6038-6042.

Banroques, J. and J. Abelson. 1989. PRP4: A protein of the yeast U4/U6 small nuclear ribonucleoprotein particle. Mol. Cell. Biol. 9: 3710-3719.

Berget, S.M. and B.L. Robberson. 1986. U1, U2 and U4/U6 small nuclear ribonucleoproteins are required for in vitro splicing but not polyadenylation. Cell 46: 691-696.

Bindereif, A. and M.R. Green. 1987. An ordered pathway of snRNP binding during mammalian pre-mRNA splicing complex assembly. EMBO I. 6: 2415-2424.

Bindereif, A., T. Wolff, and M.R. Green. 1990. Discrete domains of human U6 snRNA required for the assembly of U4/U6 snRNP and splicing complexes. EMBO /. 9: 251-255.

Black, D.L. and A.L. Pinto. 1989. U5 small nuclear ribonucleoprotein: RNA structure analysis and ATP-dependent interaction with U4/U6. Mol. Cell. Biol.9: 3350-3359.

Black, D.L. and J.A. Steitz. 1986. Pre-mRNA splicing in vitro requires intact U4/U6 small nuclear ribonucleoprotein. Cell 46: $697-704$.

Blencowe, B.J., B.S. Sproat, U. Ryder, S. Barabino, and A.I. Lamond. 1989. Antisense probing of the human U4/U6 snRNP with biotinylated 2'-OMe RNA oligonucleotides. Cell 59: $531-539$.

Boeke, J.D., J. Truehart, G. Natsoulis, and G.R. Fink. 1987. 5Fluoroorotic acid as a selective agent in yeast molecular genetics. Methods Enzymol. 154: 164-175.

Branlant, C., A. Krol, J.P. Ebel, E. Lazar, B. Haendler, and M. Jacob. 1982. U2 RNA shares a structural domain with U1, U4 and U5 RNAs. EMBO I. 1: 1259-1265.

Bringmann, P. and R. Lührmann. 1986. Purification of the individual snRNPs U1, U2, U5 and U4/U6 from HeLa cells and characterization of their protein constituents. EMBO $J$. 5: 3509-3516.

Bringmann, P., B. Appel, J. Rinke, R. Reuter, H. Theissen, and R. Lührmann. 1984. Evidence of the existence of snRNAs $\mathrm{U} 4$ and $\mathrm{U} 6$ in a single ribonucleoprotein complex and for their association by intermolecular base pairing. EMBO $\mathrm{J}$. 3: $1357-1363$

Brow, D.A. and E.P. Geiduschek. 1987. Modulation of yeast 5S rRNA synthesis in vitro by ribosomal protein YL3. $J$. Biol. Chem. 262: 13953-13958.

Brow, D.A. and C. Guthrie. 1988. Spliceosomal RNA U6 is remarkably conserved from yeast to mammals. Nature 334: 213-218.

1989. Splicing a spliceosomal RNA. Nature 337: 14-15.

Cheng, S.C. and J. Abelson. 1987. Spliceosome assembly in yeast. Genes Dev. 1: 1014-1027.

Dalrymple, M.A., S. Petersen-Bjørn, J.D. Friesen, and J.D. Beggs. 1989. The product of the PRP4 gene of $S$. cerevisiae shows homology to $\beta$ subunits of $G$ proteins. Cell 58: $811-812$.

Elledge, S.J. and R.W. Davis. 1988. A family of versatile centromeric vectors for use in the sectoring-shuffle mutagenesis assay in Saccharomyces cerevisiae. Gene 70: 303-312.

Fabrizio, P., D.S. McPheeters, and J. Abelson. 1989. In vitro assembly of yeast U6 snRNP: A functional assay. Genes Dev. 3: $2137-2150$. 
Freier, S.M., R. Kierzek, J.A. Jaeger, N. Sugimoto, M.H. Caruthers, T. Neilson, and D.H. Turner. 1986. Improved freeenergy parameters for predictions of RNA duplex stability. Proc. Natl. Acad. Sci. 83: 9373-9377.

Guthrie, C. and B. Patterson. 1988. Spliceosomal snRNAs. Annu. Rev. Genet. 23: 387-419.

Hamm, J., M. Kazmaier, and I.W. Mattaj. 1987. In vitro assembly of U1 snRNPs. EMBO I. 6: 3479-3485.

Hashimoto, C. and J.A. Steitz. 1984. U4 and U6 RNAs coexist in a single small nuclear ribonucleoprotein particle. Nucleic Acids Res. 12: 3283-3293.

Ito, H., Y. Fukuda, K. Murata, and A. Kimura. 1983. Transformation of intact yeast cells treated with alkali cations. $I$. Bacteriol. 153: 163-168.

Konarska, M.M. and P.A. Sharp. 1987. Interactions between small nuclear ribonucleoprotein particles in formation of spliceosomes. Cell 49: 763-774.

-1988. Association of U2, U4, U5, and U6 small nuclear ribonucleoproteins in a spliceosome-type complex in absence of precursor RNA. Proc. Natl. Acad. Sci. 85: 54595462.

Kunkel, T.A., J.D. Roberts, and R.A. Zakour. 1987. Rapid and efficient site-specific mutagenesis without phenotypic selection. Methods Enzymol. 154: 367-382.

Lamond, A.I., M.M. Konarska, P.J. Grabowski, and P.A. Sharp. 1988. Spliceosome assembly involves the binding and release of U4 small nuclear ribonucleoprotein. Proc. Natl. Acad. Sci. 85: 411-415.

Last, R.L., J.R. Maddock, and J.L. Woolford. 1987. Evidence for related functions of the RNA genes of Saccharomyces cerevisiae. Genetics 117: 619-631.

Lehay-Taha, M.-N., I. Reveillaud, J. Sri-Widada, C. Brunel, and P. Jeanteur. 1986. RNA-protein organization of U1, U5 and U4-U6 small nuclear ribonucleoproteins in HeLa cells. $I$. Mol. Biol. 189: 519-532.

Lerner, M.R. and J.A. Steitz. 1979. Antibodies to small nuclear RNAs complexed with proteins are produced by patients with systemic lupus erythematosus. Proc. Natl. Acad. Sci. 76: 5495-5499.

Lin, R.J., A.J. Newman, S.C. Cheng, and J. Abelson. 1985. Yeast mRNA splicing in vitro. J. Biol. Chem. 260: 14780-14792.

Lossky, M., G.J. Anderson, S.P. Jackson, and J. Beggs. 1987. Identification of a yeast snRNP protein and detection of snRNP-snRNP interactions. Cell 51: 1019-1026.

Lührmann, R. 1988. snRNP proteins. In Structure and function of major and minor small nuclear ribonucleoprotein particles (ed. M.L. Birnstiel), pp. 71-99. Springer Verlag, Heidelberg, New York, London, Paris, Tokyo.

Maniatis, T. and R. Reed. 1987. The role of small nuclear ribonucleoprotein particles in pre-mRNA splicing. Nature 325: 673-678.

Mattaj, I.W. and E.M. de Robertis. 1985. Nuclear segregation of $\mathrm{U} 2$ snRNA requires binding of specific snRNP proteins. Cell 40: $111-118$.

McClary, J.A., F. Witney, and J. Geisselsoder. 1989. Efficient site-directed in vitro mutagenesis using phagemid vectors. Biotechniques 3: 282-289.

Mottram, J., K.L. Perry, P.M. Lizardi, R. Lührmann, N. Agabian, and R.G. Nelson. 1989. Isolation and sequence of four small nuclear U RNA genes of Trypanosoma brucei subsp. brucei: Identification of the U2, U4, and U6 RNA analogs. Mol. Cell. Biol. 9: 1212-1223.

Patterson, B. and C. Guthrie. 1987. An essential yeast snRNA with a U5-like domain is required for splicing in vivo. Cell 49: 613-624.

Petersen-Bjørn, S., A. Soltyk, J.D. Beggs, and J.D. Friesen. 1989.
PRP4 (RNA4) from Saccharomyces cerevisiae: Its gene product is associated with the U4/U6 small nuclear ribonucleoprotein particle. Mol. Cell. Biol. 9: 3698-3709.

Pettersson, I., M. Hinterberger, T. Mimori, E. Gottlieb, and J.A. Steitz. 1984. The structure of mammalian small nuclear ribonucleoproteins. Identification of multiple protein components reactive with anti-(U1) ribonucleoprotein and anti-Sm autoantibodies. J. Biol. Chem. 259: 5907-5914.

Pikielny, C.W., A. Bindereif, and M.R. Green. 1989. In vitro reconstitution of snRNPs: A reconstituted U4/U6 snRNP participates in splicing complex formation. Genes Dev. 3: 479487.

Pikielny, C.W., B.C. Rymond, and M. Rosbash. 1986. Electrophoresis of ribonucleoproteins reveals an ordered assembly pathway of yeast splicing complexes. Nature 324: 341-345.

Reddy, R. and H. Busch. 1988. Small nuclear RNAs: RNA sequences, structure, and modifications. In Structure and function of major and minor small nuclear ribonucleoprotein particles (ed. M.L. Birnstiel), pp. 1-37. Springer-Verlag, Heidelberg, New York, London, Paris, Tokyo.

Riedel, N., S. Wolin, and C. Guthrie. 1987. A subset of yeast snRNAs contains functional binding sites for the highly conserved Sm antigen. Science 235: 328-331.

Rinke, J., B. Appel, M. Digweed, and R. Lührmann. 1985. Localization of a base-paired interaction between small nuclear RNAs U4 and U6 in intact U4/U6 ribonucleoprotein particles by psoralen cross-linking. I. Mol. Biol. 185: 721-731.

Sharp, P.A. 1987. Splicing messenger RNA precursors. Science 235: 766-771

Sherman, F., G.R. Fink, and C.W. Lawrence. 1974. Methods in yeast genetics. Cold Spring Harbor Laboratory, Cold Spring Harbor, New York.

Siliciano, P.G., D.A. Brow, H. Roiha, and C. Guthrie. 1987. An essential snRNA from $S$. cerevisiae has properties predicted for U4, including interaction with U6-like snRNA. Cell 50: $585-592$.

Tollervey, D. and I.W. Mattaj. 1987. Fungal small nuclear ribonucleoproteins share properties with plant and vertebrate U-snRNPs. EMBO I. 6: 469-476.

Wise, J.A., D. Tollervey, D. Maloney, H. Swerdlow, E.J. Dunn, and C. Guthrie. 1983. Yeast contains small nuclear RNAs encoded by single copy genes. Cell 35: 743-751.

Xu, Y., S. Petersen-Bjørn, and J.D. Friesen. 1990. The PRP4 (RNA4) protein of Saccharomyces cerevisiae is associated with the $5^{\prime}$ portion of the U4 snRNA. Mol. Cell. Biol. 10: $1217-1225$. 


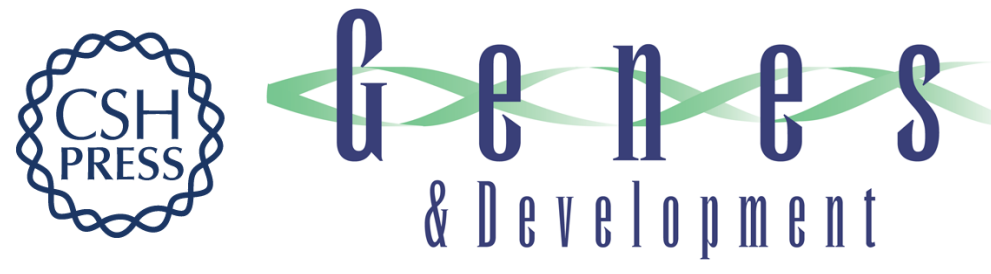

\section{Domains of yeast U4 spliceosomal RNA required for PRP4 protein binding, snRNP-snRNP interactions, and pre-mRNA splicing in vivo.}

R Bordonné, J Banroques, J Abelson, et al.

Genes Dev. 1990, 4:

Access the most recent version at doi:10.1101/gad.4.7.1185

References This article cites 49 articles, 20 of which can be accessed free at: http://genesdev.cshlp.org/content/4/7/1185.full.html\#ref-list-1

License

Email Alerting

Service

Receive free email alerts when new articles cite this article - sign up in the box at the top right corner of the article or click here.

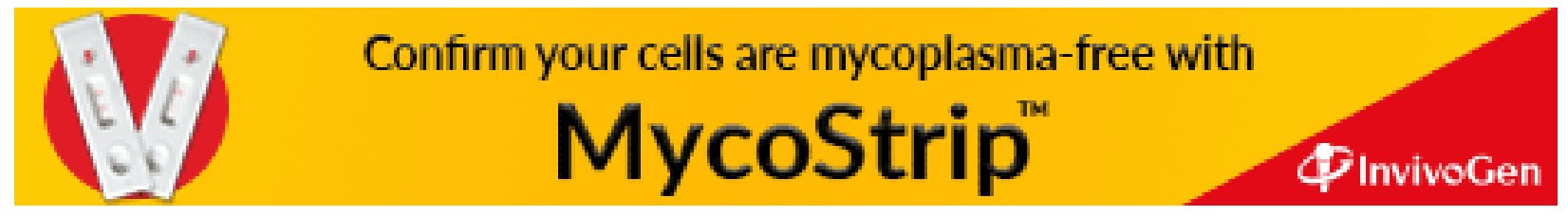

